\title{
Tratamento com Infliximabe da Doença de Behçet Ativa ${ }^{(*)}$
}

\section{Therapy with Infliximab in Active Behçet's Disease}

\author{
Alexandre Wagner Silva de Souza ${ }^{(1)}$, Paula Pileggi ${ }^{(1)}$, Elisa Terezinha Hachbarth ${ }^{(2)}$
}

\section{RESUMO}

Os autores descrevem o caso de uma paciente de 41 anos de idade com diagnóstico de doença de Behçet, diagnosticada em abril de 2000. A paciente apresentava envolvimento mucocutâneo, articular e neurológico persistentes, apesar do tratamento com colchicina, corticosteróides e metotrexato, durante os três anos que se seguiram ao diagnóstico. Em abril de 2003, a paciente mantinha-se com a doença ativa, necessitando de altas doses de corticosteróides e de metotrexato. Optou-se, então, pela administração do infliximab, $3 \mathrm{mg} / \mathrm{kg}$ por via endovenosa. Uma semana depois, havia ocorrido regressão completa das manifestações da doença de Behçet nesta paciente.

Palavras-chave: doença de Behçet, infliximab, tratamento.

\section{INTRODUÇÃO}

A doença de Behçet (DB) tem etiologia desconhecida e se caracteriza por surtos inflamatórios recorrentes. Suas manifestações mais comuns incluem úlceras orais e genitais, uveíte e lesões cutâneas ${ }^{(1)}$. A susceptibilidade à DB é fortemente associada ao HLA-B51, embora agentes ambientais tenham sido implicados na patogênese ${ }^{(2)}$. A prevalência da DB é maior em países orientais, principalmente na Turquia (80 a 370 casos/100.000 habitantes), mas também é elevada no Japão, na Coréia, na China, no Irã e na Arábia Saudita $(13,5 \text { a } 20 \text { casos } / 100.000 \text { habitantes })^{(3)}$.

$\mathrm{Na}$ etiopatogenia da DB, destacam-se a vasculite, a hiperatividade de neutrófilos e os fenômenos auto-imunes, incluindo a presença de linfócitos $\mathrm{T}$ auto-reativos para a proteína de choque térmico 60 . As citocinas encontradas em altos níveis na DB são o fator de necrose tumoral (TNF- $\alpha$ ) e as interleucinas IL-1 e IL-8. Em pacientes com

\begin{abstract}
The authors describe the case of a 41 years old woman with the diagnosis of Behçet's syndrome since April 2000, when she presented mucocutaneous, articular and ocular manifestations. The disease remained active despite of the treatment with colchicine, corticosteroid and methotrexate, during the three years following diagnosis. In April 2003, the patient still needed high doses of corticosteroid and methotrexate. Nevertheless, the disease remained active. Treatment with infliximab was then started with intravenous $3 \mathrm{mg} / \mathrm{Kg}$ and, one week later, all the manifestations of this patient were in complete remission.
\end{abstract}

Keywords: Behçet's disease, infliximab, treatment.

a DB ativa, foram observados altos níveis de TNF- $\alpha$ e de seu receptor solúvel no sangue periférico e no humor aquoso $^{(2,4-5)}$.

A DB não apresenta sinais clínicos ou laboratoriais patognomônicos e os pacientes podem ser classificados de acordo com os critérios propostos em 1990 pelo Grupo Internacional de Estudos em Doença de Behçet (Tabela 1) ${ }^{(6)}$.

$\mathrm{Na} \mathrm{DB}$, a escolha do tratamento deve ser individualizada, de acordo com as manifestações apresentadas pelo paciente. As manifestações mucocutâneas podem ser controladas com o uso de colchicina e corticosteróides tópicos. Em casos refratários, utiliza-se corticosteróides sistêmicos ou talidomida. Dá-se prioridade ao tratamento de manifestações graves, como os envolvimentos: gastrintestinal, do sistema nervoso central, ocular e de grandes vasos, que requerem doses altas de corticosteróides e/ou o uso de imunossupressores, incluindo azatioprina, metotrexato, ciclosporina A, clorambucil ou ciclofosfamida ${ }^{(1,7,8)}$.

\footnotetext{
* Trabalho realizado no Serviço de Reumatologia do Hospital Professor Edmundo Vasconcelos, São Paulo-SP, Brasil. Recebido em 08/01/2004. Aprovado, após revisão, em 29/07/2004.

1. Mestre em reumatologia e médico assistente do Serviço de Reumatologia do Hospital Professor Edmundo Vasconcelos, São Paulo-SP, Brasil.

2. Doutor em reumatologia e médico assistente do Serviço de Reumatologia do Hospital Professor Edmundo Vasconcelos, São Paulo-SP, Brasil.

Endereço para correspondência: Alexandre Wagner Silva de Souza. Serviço de Reumatologia do Hospital Professor Edmundo Vasconcelos. Rua Borges Lagoa, 1450, Vila Clementino, CEP 04038-905, São Paulo, SP, Brasil.
} 
TABELA 1

Critérios diagnósticos da doença de BehÇET ${ }^{(6)}$

\begin{tabular}{|c|c|}
\hline Manifestações & Definição \\
\hline Ulceração oral recorrente & $\begin{array}{l}\text { Úlceras maiores ou menores ou herpetiformes, observadas por médico ou paciente, com pelo menos três } \\
\text { episódios em período de um ano }\end{array}$ \\
\hline Ulceração genital recorrente & Úlcera aftosa ou cicatriz observada pelo médico ou pelo paciente \\
\hline Lesão ocular & $\begin{array}{l}\text { Uveíte anterior ou posterior, células no vítreo ao exame da lâmpada de fenda ou vasculite retiniana } \\
\text { detectadas por oftalmologista }\end{array}$ \\
\hline Lesões cutâneas & $\begin{array}{l}\text { Eritema nodoso observado por médico ou paciente, pseudofoliculite ou lesões pápulo-pustulosas ou } \\
\text { acneiformes em pacientes fora do período de adolescência e que não estejam em uso de corticosteróides }\end{array}$ \\
\hline Teste da patergia positivo & Teste considerado positivo por médico em 24 a 48 horas de sua realização \\
\hline
\end{tabular}

Nos últimos anos, diversos relatos anedóticos do uso de terapia anti-TNF- $\alpha$ na DB com resposta significativa vêm sendo publicados em diversos países ${ }^{(9)}$. O objetivo deste trabalho é descrever o primeiro caso brasileiro de uso de terapia anti-TNF- $\alpha$ na DB e revisar essa nova perspectiva terapêutica nesta doença, em cuja patogênese o TNF- $\alpha$ desempenharia papel central.

\section{RELATO DE CASO}

Mulher de 41 anos recebeu diagnóstico de doença de Behçet em abril de 2000, quando apresentava úlceras orais e genitais recorrentes há dois anos, além de ter apresentado quadro recente de eritema nodoso. A paciente foi tratada inicialmente com prednisona $20 \mathrm{mg} /$ dia e colchicina, obtendo melhora acentuada das manifestações mucocutâneas. Naquela ocasião, hemograma, creatinina e enzimas hepáticas foram normais e sorologias para HIV e vírus da hepatite B e C foram negativas. A avaliação oftalmológica foi normal e a pesquisa de anticorpos antinucleares foi negativa. Ao se iniciar a redução da prednisona, um mês após sua introdução, a paciente passou a apresentar recorrência das úlceras orais e artrite em grandes articulações, incluindo joelhos, tornozelos e cotovelos e foi então introduzido o metotrexato na dose de $7,5 \mathrm{mg} / \mathrm{semana}$, a dose de prednisona retornou para $20 \mathrm{mg}$ /dia e a colchicina foi mantida. Houve melhora rápida das úlceras orais, mas a melhora do quadro articular foi paulatina. Manteve-se em dose estável de prednisona, colchicina e de metotrexato até abril de 2001. Nessa época, a paciente encontrava-se assintomática e foi iniciada a diminuição da dose de prednisona. Entretanto, a mesma evoluiu com cefaléia holocraniana de forte intensidade e houve recorrência do eritema nodoso. A ressonância nuclear magnética do encéfalo e o exame do líquido cefalorraquiano foram normais. A dose de prednisona foi elevada novamente para $20 \mathrm{mg} / \mathrm{dia}$ e foram mantidos colchicina e metotrexato $(7,5 \mathrm{mg} / \mathrm{semana})$. Houve melhora da cefaléia e das lesões cutâneas.

Nos meses subseqüentes, a paciente experimentou diversas recorrências do quadro mucocutâneo, da cefaléia e persistência do quadro articular, necessitando utilizar doses maiores de prednisona e de metotrexato, que passou a ser administrado por via parenteral, em doses até de $25 \mathrm{mg}$ / semana. A paciente teve episódio de olho vermelho, mas a avaliação oftalmológica evidenciou apenas pingüeculite. Em abril de 2003, devido à persistência da atividade mucocutânea, articular e neurológica, a despeito do tratamento empregado, foram iniciadas infusões de infliximabe, na dose de $3 \mathrm{mg} / \mathrm{kg}$, no tempo zero, em duas semanas e em seis semanas. A paciente não experimentou reações adversas com o infliximabe. O metotrexato foi diminuído para $7,5 \mathrm{mg} / \mathrm{semana}$, colchicina e a prednisona foi reduzida para $10 \mathrm{mg} /$ dia. Houve melhora total das manifestações clínicas da paciente uma semana após a infusão do infliximabe. Foram administradas doses de manutenção de infliximabe $3 \mathrm{mg} / \mathrm{kg}$, a cada 8 semanas, até dezembro de 2003. Atualmente, um ano após o início das infusões de infliximabe e sete meses após a suspensão do infliximabe, a paciente mantém-se assintomática. Utiliza apenas colchicina $1,0 \mathrm{mg} /$ dia e metotrexato $7,5 \mathrm{mg} /$ semana.

\section{DISCUSSÃO}

A escolha do tratamento na DB depende da manifestação clínica apresentada pelo paciente, entre estas, as manifestações oculares, neurológicas, gastrintestinais e lesões de 
grandes vasos merecem atenção especial e requerem o uso de corticosteróides em altas doses e de imunossupressores $^{(1,3,8)}$. Relatos de caso e séries de casos têm demonstrado os efeitos benéficos do uso do infliximabe a curto prazo na DB refratária à terapia com imunossupressores. Nesses casos, a duração do tratamento variou de uma a quatro infusões, em um intervalo que variou até os seis meses. Foram utilizadas doses de $3 \mathrm{mg} / \mathrm{kg}, 5 \mathrm{mg} / \mathrm{kg}$ e $10 \mathrm{mg} / \mathrm{kg}$. O uso de infliximabe foi motivado por diferentes manifestações refratárias da DB nos casos relatados pela literatura, incluindo manifestações mucocutâneas, gastrintestinais, articulares, oculares e neurológicas. Em todos os casos, houve remissão completa do quadro após a infusão do infliximabe ${ }^{(9-13)}$. Há a necessidade da realização de ensaios clínicos controlados e randômicos com o uso do infliximabe na DB para se comparar com a terapia convencional e para se determinar o regime terapêutico adequado. Alguns estudos abertos estão sendo conduzidos para se avaliar o efeito a longo prazo do uso do infliximabe na $\mathrm{DB}^{(9)}$.

Quanto ao etanercepte, outro agente anti-TNF- $\alpha$, foram apresentados dois estudos na Décima Conferência Internacional na Doença de Behçet em junho de 2002, em

\section{REFERÊNCIAS}

1. Sakane T, Takeno M, Suzuki N, Inaba GA: Behçet's Disease. N Eng J Med 341:1284-91, 1999.

2. Direskeneli H: Behçet's disease: infectious aetiology, new autoantigens, and HLA-B51. Ann Rheum Dis 60:996-1002, 2001.

3. Kaklamani VG, Variopoulus G, Kaklamanis PG: Behçet's disease. Semin Arthritis Rhem 27:197-217, 1998.

4. Ehrlich GE: Vasculitis in Behçet's disease. Int Rev Immunol 14: 81-8, 1997.

5. Kaneko S, Suzuki N, Yamashita N, et al: Characterization of T cells specific for an epitope of human 60-kD heat shock protein (hsp) in patients with Behçet's disease (BD) in Japan. Clin Exp Immunol 108:204-12, 1997

6. International Study Group for Behçet's Disease: Criteria for diagnosis of Behçet's disease. Lancet 335:1078-80, 1990.

7. Saenz A, Ausejo M, Shea B, et al: Pharmacotherapy for Behçet's syndrome. Cochrane Database Syst Rev 2:CD001084, 2000.
Berlim. Nesses estudos, houve melhora das úlceras orais, das lesões cutâneas e da artrite, além de melhora da acuidade visual em pacientes com uveíte refratária e $\mathrm{DB}^{(9)}$.

Neste caso relatado, a paciente apresentava manifestações mucocutâneas, articulares e neurológicas refratárias ao uso de corticosteróide, colchicina e metotrexato, necessitando do uso dessas medicações em altas doses e mesmo assim, sem obter controle das manifestações da doença. De forma semelhante aos casos relatados pela literatura, esta paciente obteve remissão completa do quadro após a segunda infusão de infliximab e não experimentou eventos adversos. Atualmente, a paciente mantém-se em remissão do quadro, sete meses após a última infusão de infliximabe.

A experiência acumulada pela literatura sugere que a administração de infliximabe resulta em supressão rápida de diferentes manifestações da DB, pelo menos a curto prazo. Este é o primeiro relato do uso do infliximabe em DB no Brasil e a evolução da paciente aqui relatada foi semelhante ao encontrado na literatura. O uso de infliximabe desponta como uma terapia promissora para a DB não responsiva aos recursos terapêuticos convencionais.

8. Yazici H, Yurdakul S, Hamuryudan V: Behçet disease. Curr Opin Rheumatol 13:18-22, 2001.

9. Sfikakis PP: Behçet's disease: a new target for anti-tumor necrosis factor treatment. Ann Rheum Dis 61 (Suppl 2):51-3, 2002.

10. Goossens PH, Verburg RJ, Breedveld FC: Remission of Behçet's syndrome with tumor necrosis factor a blocking therapy. Ann Rheum Dis 60:637, 2001.

11. Robertson LP, Hickling P: Treatment of recalcitrant orogenital ulceration of Behçet's syndrome with infliximab. Rheumatol 40:4734, 2001.

12. Munoz-Fernandez S, Hidalgo V, Fernandez-Melon J, et al: Effect of infliximab on threatening panuveitis in Behçet's disease. Lancet 358:1644, 2001.

13. Rosenbaum M, Rosner I, Portnoy E: Remission of Behçet's syndrome with TNFa blocking treatment. Ann Rheum Dis 61: 283-4, 2002 